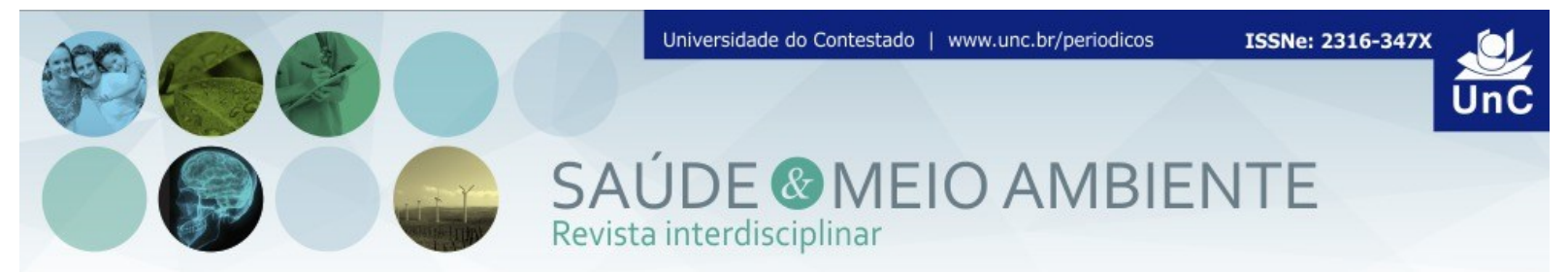

\title{
UMA REFLEXÃO SOBRE MUDANÇAS CLIMÁTICAS, SAÚDE E MEIO AMBIENTE NO SEMIÁRIDO NORDESTINO
}

\author{
Maria Iderlania de Freitas Sousa ${ }^{1}$ \\ Josafá Justino Barbosa ${ }^{2}$ \\ Celme Torres Ferreira Costa ${ }^{3}$
}

\begin{abstract}
RESUMO: Este ensaio abordou a questão das mudanças climáticas no semiárido nordestino, a partir da reflexão de eventos históricos fundamentais para a discussão que envolve o meio ambiente, a saúde e as alterações do clima. Diferentes nações estão tomando medidas de enfrentamento a essas mudanças, no Brasil ações em nível federal também se somam as ações estaduais e ainda timidamente as municipais para convivência com este novo momento. As regiões brasileiras são peculiares, cada ecossistema responde de maneira singular as modificações de temperatura e já são afetadas pelas modificações do clima, comprometendo ecossistemas e desencadeando novos problemas nas cidades. Tratou-se em especial das repercussões sobre o semiárido por ser uma região bastante vulnerável, devido a extensas áreas de desertificação aliado a seca constante e as questões socioambientais. $\mathrm{O}$ bioma caatinga possui ampla diversidade biológica que tem muito a contribuir para o desenvolvimento sustentável do país. São apontadas alternativas sustentáveis para convivência com as atuais mudanças do clima no semiárido uma vez que a preservação da diversidade biológica é reconhecidamente de extrema importância para a sobrevivência humana. Na valorização dos saberes locais em articulação com as políticas públicas se tem uma maneira de atenuar as mudanças regionais de clima e possibilitar o enfrentamento das mudanças climáticas globais.
\end{abstract}

Palavras chave: Saúde. Mudanças Climáticas. Semiárido. Meio Ambiente.

\footnotetext{
${ }^{1}$ Bióloga. Fisioterapeuta. Mestre em Desenvolvimento Regional Sustentável (Universidade Federal do Cariri - UFCA). Professora do Departamento de Ciências Biológicas da Universidade Regional do Cariri - URCA. Crato - CE. Brasil. E-mail: iderbio@hotmail.com

${ }^{2}$ Fisioterapeuta. Especialista em Fisiologia do Exercício (Universidade Vale do Acaraú - UVA). Professor do Departamento de Ciências Biológicas da Universidade Regional do Cariri - URCA. Crato - CE. Brasil. E-mail: josafa.barbosa@hotmail.com

${ }^{3}$ Engenheira Civil. Doutora em Engenharia Civil com ênfase em Recursos Hídricos (Universidade Federal do Ceará). Pró-reitora de Pesquisa e Inovação da Universidade Federal do Cariri - UFCA. Juazeiro do Norte - CE. Brasil. E-mail: celmetorres@gmail.com
} 


\title{
A REFLECTION ON CLIMATE CHANGE, HEALTH AND THE ENVIRONMENT IN NORTHEASTERN SEMIARID
}

\begin{abstract}
This paper addressed the issue of climate change in semi-arid northeast, from the reflection of key historical events for the discussion involving the environment, health and climate change. Different nations are taking steps to cope with these changes, in Brazil actions at the federal level also added shares timidly state and the municipal coexistence with this new moment. The Brazilian regions are unique, each unique ecosystem responds to changes in temperature and are already affected by climate change, affecting ecosystems and triggering new problems in cities. This was particularly the impact on the semiarid region to be a very vulnerable due to extensive areas of desertification ally constant drought and environmental issues. The savanna biome has broad biological diversity that has much to contribute to the sustainable development of the country. Are pointed sustainable alternatives for coping with the current changes in the semiarid climate since the preservation of biological diversity is recognized as extremely important for human survival. In appreciation of local knowledge in conjunction with public policies has a way of alleviating regional changes in climate and enable coping with global climate change.
\end{abstract}

Keywords: Health. Climate Change. Semiarid. Environment.

\section{INTRODUÇÃO}

A sobrevivência do homem sempre dependeu dos recursos naturais e ao longo do tempo a exploração da natureza contribuiu para o clímax ou a decadência de grandes civilizações. Ao longo da história somou-se ao processo natural às atividades antrópicas resultando em contribuições adicionais para a destruição do meio ambiente com a finalidade de obter recursos para seu bem-estar e para o lucro.

A revolução industrial representou um divisor para humanidade, as máquinas revolucionaram as relações de trabalho e transformou artesãos em proletários, ambientes naturais em ambientes construídos, a subsistência em salário, mudando profundamente a organização social.

Durante muitos séculos predominou a ideia de que a natureza existia somente para satisfazer as vontades humanas, não se questionando os limites desse usufruto. No início do século $\mathrm{XX}$ foram dados os primeiros passos para as discussões multilaterais que se intensificaram nas décadas seguintes, enquanto o mundo assistia as chuvas ácidas, o aumento da poluição, a contaminação por mercúrio na baia de Mimata e o comprometimento das reservas hídricas.

Nas últimas décadas, a comunidade internacional adotou inúmeros tratados de grande importância na área ambiental como a Convenção de Basiléia em 1989 cujo objetivo era reduzir a realocação internacional do lixo, a Conferência de Estocolmo e a ECO-92 (PEARSON, 2011). 
As mudanças climáticas são uma realidade que já atinge diversas partes do planeta, alterando ecossistemas, modificando os regimes de precipitação, transformando o ambiente natural e as relações bióticas e abióticas.

O semiárido nordestino é uma área de extrema vulnerabilidade, pela localização geográfica e pela disposição geomorfológica, mas principalmente pela grande biodiversidade que possui em fauna e flora, ainda não totalmente catalogadas, mas em risco de desaparecimento pelos fatores climáticos e antrópicos.

Este trabalho objetivou refletir acerca das mudanças climáticas e suas repercussões sobre a saúde e o meio ambiente no semiárido nordestino, através de uma abordagem histórica envolvendo os tratados ambientais, conferências e convenções sobre alterações climáticas.

\section{METODOLOGIA}

Esta investigação caracterizou-se como pesquisa bibliográfica de natureza exploratória-descritiva através do método qualitativo, cuja coleta de dados foi realizada nas bases de dados SciELO e periódicos CAPES no período entre maio e agosto de 2013. Para tanto, utilizaram-se os descritores para a língua portuguesa: "semiárido, sustentabilidade, mudanças climáticas, saúde e meio ambiente".

Foram inclusos publicações em português na forma de artigos e informações digitais provindas do Painel Intergovernamental Sobre Mudanças Climáticas (IPCC), Instituto Nacional do Semiárido (INSA), Ministério da Ciência e Tecnologia, e do Ministério do Meio Ambiente. Priorizaram-se aqueles de maior interesse para a discussão do assunto.

O material foi avaliado mediante a leitura dos resumos e selecionado aqueles que atendiam aos objetivos do estudo, em seguida foi averiguado cada artigo na íntegra visando ordenar e sistematizar as informações necessárias para a construção do manuscrito.

\section{RESULTADOS E DISCUSSÕES}

Foram analisados 09 artigos publicados entre 2005 e 2013, a partir de suas ideias foi traçada uma discussão acerca das mudanças climáticas, saúde e meio ambiente no semiárido nordestino, através de um delineamento do processo histórico envolvendo os tratados ambientais, conferências e convenções sobre alterações climáticas, visando entender como essas mudanças podem ser 
percebidas e como ainda afetarão o campo e as cidades de acordo com as projeções estabelecidas para os próximos anos.

CONFERÊNCIA DE ESTOCOLMO - 1972

O primeiro tratado global na área do meio ambiente foi firmado por ocasião da Conferência de Estocolmo, convocada pela ONU em virtude da preocupação crescente, sobretudo nos países desenvolvidos, com a degradação ambiental do planeta.

A Conferência da ONU sobre o ambiente humano ocorreu na Suécia em junho de 1972 atraiu um público diferenciado das demais convenções, não recebeu apenas a comunidade científica, mas recebeu representações diplomáticas de vários países. Esta conferencia consegui aprovar a Declaração Sobre o Meio Ambiente Humano, com 110 recomendações e 26 princípios (PEARSON, 2011).

As diretrizes estabelecidas criaram um plano de ação para os países e suas relações internacionais, oferecendo bases sólidas para a preservação ambiental em nível mundial. Este documento não tinha força de lei, e não foi seguido na íntegra pelos países participantes de Estocolmo 72, mas serviu como alicerce para 0 aperfeiçoamento de documentos futuros como o relatório Brundtland marco teórico para a expressão desenvolvimento sustentável e despertou outros Estados para os problemas ambientais.

Nasceram nessa conferência às primeiras reflexões sobre os efeitos da industrialização sobre o meio ambiente e sobre a sociedade que interage com este meio e no mesmo. Tais ideias ao serem apresentadas, levantaram questionamentos não somente sobre as ações dos homens sobre a natureza, mas geraram discussões políticas, econômicas e sociais (BARBIERI, 2007).

Na Declaração de Estocolmo consta que o homem é ao mesmo tempo obra e construtor do meio ambiente e que a proteção e o melhoramento do meio ambiente humano é uma questão fundamental que afeta o bem-estar dos povos e o desenvolvimento econômico, sendo assim é necessário que cidadãos e comunidades, empresas e instituições, em todos os planos, aceitem as responsabilidades que possuem e que todos participem equitativamente, nesse esforço comum (MINISTÉRIO DO MEIO AMBIENTE, 2013).

Esta Conferência também foi marcada pela disposição de dois blocos, de um lado países desenvolvidos eram defensores da intocabilidade do meio ambiente, por outro lado os países subdesenvolvidos rejeitavam qualquer tentativa de privá-los dos benefícios advindos da tecnologia, porque via na industrialização a sua única saída para problemas como fome, miséria e falta de saneamento, causou uma ruptura na visão tradicionalista e teve uma grande repercussão na evolução dos debates ambientais, pois pela primeira vez os países de terceiro mundo puderam falar de 
suas realidades e deixar claro que as questões ambientais estão diretamente ligadas ao contexto social.

\section{CONFERÊNCIA DA ONU SOBRE MEIO AMBIENTE E DESENVOLVIMENTO - 1992}

O progresso em matéria ambiental foi insignificante nos vinte anos que se seguiram à Conferência de Estocolmo aliado a um fator impulsionante dos debates ambientais foi a divulgação do primeiro relatório do Painel Intergovernamental Sobre Mudanças Climáticas (IPCC) alertando a comunidade científica sobre o aumento das concentrações de gases de efeito estufa.

Por decisão da ONU foi convocada uma nova conferência, a ECO-92 realizada no Rio de Janeiro. Estiveram presentes 178 delegações com chefes de estado de 115 países. A cúpula da terra como também ficou conhecida deu enorme visibilidade a uma série de questões ambientais, além de produzir importantes documentos entre eles as Convenções-Quadro sobre mudança do clima e sobre biodiversidade.

\section{CONVENÇÃO-QUADRO SOBRE MUDANÇAS CLIMÁTICAS}

Criada na ECO-92, atualmente conta com 192 países, essa convenção buscou reunir países para estabilizar as concentrações de gases de efeito estufa, os governos que assinaram tornaram-se partes da convenção, propondo-se a elaborar uma estratégia global para proteger o sistema climático (BNDES, 1999).

O monitoramento ocorre pela Conferência das Partes (COP) que é o órgão supremo da convenção com a responsabilidade de manter regularmente a implementação da convenção, utilizando como ferramenta reuniões periódicas em diversos locais do mundo, a primeira COP ocorreu em 1995 (Berlim, Alemanha) e a última, a COP 18 foi realizada em 2012 em Doha, Catar (BRASIL. MINISTÉRIO DO MEIO AMBIENTE, 2013).

São atribuições da convenção, criar instrumentos e mecanismos para promover a gestão sustentável e demais condições que possibilitem alcançar a estabilização das concentrações de gases de efeito estufa na atmosfera em um nível que não interfira perigosamente no sistema climático (BNDES, 1999).

Os principais gases de efeito estufa são o dióxido de carbono $\left(\mathrm{CO}_{2}\right)$, o ozônio $\left(\mathrm{O}_{3}\right)$, o metano $\left(\mathrm{CH}_{4}\right)$ e o óxido nitroso $\left(\mathrm{N}_{2} \mathrm{O}\right)$, correspondem a menos de $0,001 \%$ da atmosfera que é composta por oxigênio (21\%) e nitrogênio (78\%) estes são fundamentais para preservar o calor no planeta, no entanto conforme previsões do 
IPCC (2007), caso as emissões continuem aumentando ocorrerá um aquecimento da ordem de 1,5 a $4,5^{\circ} \mathrm{C}$ nos próximos 100 anos e determinarão mudanças significativas nos ciclos de chuva e vento, e no nível do mar.

O problema teve origem logo que as atividades humanas começaram a emitir gases de efeito estufa em larga escala, aumentando sua concentração na atmosfera, no entanto, o efeito estufa não pode ser atribuído apenas a industrialização, a agricultura, o desmatamento, a pecuária e a ampliação de centros urbanos também são responsáveis por este fenômeno.

\section{CONVENÇÃO SOBRE BIODIVERSIDADE}

A Convenção sobre diversidade biológica também foi um dos documentos resultantes das discussões da ECO-92. O texto inicial previa uma série de ações a serem implantadas pelos países participantes para preservar a diversidade biológica, tendo em vista sua a sensível perda e diminuição ao longo das últimas décadas e a importância de sua conservação para o equilíbrio das condições de vida na terra.

Assinado por mais de 160 países, a convenção oferece um arcabouço de direcionamentos gerais para diversos outros tratados mais específicos assinados posteriormente como o Protocolo de Cartagena sobre Biossegurança, as diretrizes para o turismo sustentável e a biodiversidade, para a prevenção, controle e erradicação das espécies exóticas invasoras e os princípios e diretrizes da abordagem ecossistêmica para a gestão da biodiversidade. De acordo com o Ministério do Meio Ambiente (2000), os objetivos desta convenção foram:

[...] a conservação da diversidade biológica, a utilização sustentável de seus componentes e a repartição justa e equitativa dos benefícios derivados da utilização dos recursos genéticos, mediante, inclusive, o acesso adequado aos recursos genéticos e a transferência adequada de tecnologias pertinentes, levando em conta todos os direitos sobre tais recursos e tecnologias, e mediante financiamento adequado (BRASIL. MINISTÉRIO DO MEIO AMBIENTE, 2000).

A Organização das Nações Unidas declararam de 2011 a 2020 a década da biodiversidade, quando irá reforçar o debate e incrementar o número de ações para educação e conscientização e reverter às perdas da diversidade biológica. Será também um período onde haverá um maior incentivo aos governos para desenvolvimento, aplicação e divulgação de um Plano de Estratégico para Diversidade Biológica.

Planos, documentos específicos e atuações mais específicas para reverter as perdas biológicas mundial e localmente são resultados diretos das discussões fomentadas pela Convenção sobre a Diversidade Biológica da ECO-92 e demonstra a necessidade de se rever a relação humana com as espécies pensando novas formas de conceber seu uso sustentável. 


\section{O SEMIÁRIDO NORDESTINO}

As regiões semiáridas caracterizam-se por um elevado saldo positivo de energia solar e déficit hídrico. A dimensão territorial do semiárido brasileiro possui atualmente uma extensão de $969.589,4 \mathrm{~km}^{2}$, com uma população de 48 milhões de habitantes, o que corresponde a $20 \%$ da população brasileira (INSA, 2013).

A delimitação desta área está fundamentada nos seguintes critérios: precipitações médias anuais iguais ou inferiores $800 \mathrm{~mm}$; insolação média de 2.800 h/ano; temperaturas médias anuais entre 23 a $27^{\circ} \mathrm{C}$; índice de aridez menor que 0,5 ; irregularidade do regime de chuvas e probabilidade de ocorrência de seca maior que $60 \%$ (MENEZES et al., 2012).

O semiárido nordestino tem como traço principal as frequentes secas que podem ser caracterizadas pela ausência, escassez ou alta variabilidade espacial e temporal das chuvas. Ocupa cerca de $48 \%$ da região nordeste, de geologia bastante variada, apresentando predomínio de rochas cristalinas e áreas sedimentares (INSA, 2013).

O ecossistema caatinga se estende pela totalidade do estado de ceará, ocupa $9,92 \%$ do território brasileiro, está presente em todos os estados do nordeste e em pequenas porções do estado de minas gerais. O bioma caatinga é predominante, no entanto, pode-se encontrar mata úmida localizada nas porções mais elevadas, tais como a chapada do Araripe, áreas de cerrado e carrasco (SILVA, 2013).

Segundo Andrade et al. (2010), a cobertura vegetal é diversa, abrigando mais de 1.900 espécies catalogadas. Já foram descritas 510 espécies de aves, 240 de peixes de água doce, 143 de mamíferos, 47 de lagartos, 52 de serpentes e 48 espécies de anfíbios, além dos grupos de invertebrados.

É de extrema importância ressaltar que grande parte das espécies animais e vegetais são endêmicas desta região (318 espécies da flora, 135 peixes, 24 de espécies répteis e anfíbios, 12 espécies de mamíferos e 30 de invertebrados), além disso, $90 \%$ das espécies de aves se reproduzem na mesma região, ou seja, não estão nela apenas no período de migração (ANDRADE et al., 2010).

A preservação desta diversidade é reconhecidamente de extrema importância para a sobrevivência humana. Na Conferência sobre Biodiversidade é ressaltada ainda a responsabilidade dos governos em relação à sua preservação e recuperação, atuando com investimentos financeiros diretos e em pesquisa e educação. A preocupação com a relação das comunidades locais com as espécies também deve ser levada em consideração na atuação de políticas públicas e na gestão ambiental, valorizando, inclusive o forte papel que a mulher exerce nestas áreas.

As regiões semiáridas do mundo estarão entre as mais afetadas pelos impactos das mudanças climáticas globais. De acordo com Marengo et al. (2011), no 
Nordeste brasileiro choverá menos e mais irregularmente além do agravamento e maior constância de secas, devido a elevação da temperatura.

Segundo Nobre (2011), a vulnerabilidade do bioma caatinga aos efeitos das mudanças do clima representa um fator de pressão para a desertificação nesta região, além de levar ao desaparecimento de espécies da fauna e flora nativos.

Nos processos que envolvem mudanças na cobertura vegetal, o clima pode ser seriamente afetado, uma vez que a atmosfera é sensível às características da superfície continental. A conversão da vegetação natural para áreas agrícolas ou de pastagem afetam as trocas de energia, água e carbono entre a atmosfera e a superfície continental.

De acordo com Silva (2013), aproximadamente $40 \%$ da cobertura florestal do nordeste fica no semiárido e é responsável por $90 \%$ da demanda de produtos florestais, $70 \%$ da energia utilizada pelas famílias e participa com $15 \%$ da renda global dos produtores; $25 \%$ da energia primária do setor industrial são advindos da lenha e do carvão vegetal, que ocupam o primeiro e segundo lugar na matriz energética da região.

O semiárido apresenta problemas ambientais de degradação que podem ser ainda ampliadas devido à interferência humana. A substituição da vegetação natural da caatinga por agropecuária assim como a degradação da caatinga, podem causar modificações nos processos de superfície na região semiárida que induzem mudanças microclimáticas, em uma escala regional podem ser significativas dependendo do tamanho da área transformada (ANDRADE et al., 2010).

Todos os estados da Região Nordeste são vulneráveis a desertificação, na Paraíba, $70 \%$ do território onde vivem 1,66 milhão de pessoas já sofre com o problema. No Rio Grande do Norte $97,5 \%$ do território é vulnerável à desertificação. Este fenômeno se inicia com a destruição da caatinga aliado ao mau uso dos recursos hídricos e a degradação do solo. As mudanças climáticas podem agravar o problema, tornando as áreas semiáridas em zonas áridas, com raras chuvas (VIOLA, 2002).

Modificações do habitat, conversão de terras e desmatamento para criação de estradas e agricultura alteram as condições ecológicas e podem levar à extinção de espécies. A perda da biodiversidade afeta os ecossistemas tanto aquáticos como terrestres (CARVALHO et al., 2005).

A diversidade de espécies também é importante na ecologia das doenças infecciosas, particularmente zoonoses transmitidas por vetores. A alta diversidade de espécies de hospedeiros vertebrados pode desempenhar um papel benéfico por impedir o domínio de determinadas espécies que atuam como reservatórios principais do patógeno, e assim podem reduzir o risco de doenças. 


\section{ALTERAÇÕES DO CLIMA: REPERCUSSÕES SOBRE A SAÚDE E O MEIO AMBIENTE}

O clima da terra está sempre mudando, durante os últimos 150 mil anos o clima global variou entre dois estados quente-úmido e frio-seco em decorrência de processos naturais como as variações de órbita, erupções vulcânicas e alterações na radiação solar. Uma certa variabilidade é natural tais como as secas e enchentes, ocorrendo a intervalos que vão de estações a séculos, o que significa que nunca se pode esperar que um ano ou década seja igual ao seguinte (MARENGO et al., 2011).

Embora o clima tenha sempre variado de modo natural, as emissões excessivas de dióxido de carbono, metano e óxido nitroso podem provocar mudanças permanentes e irreversíveis no clima, originando novos padrões no regime dos ventos, pluviosidade e circulação dos oceanos (BNDES, 1999).

As atividades antrópicas somadas ao processo natural estão resultando em contribuições adicionais de gases de efeito estufa, acentuando a concentração dos mesmos na atmosfera. De acordo com Ventura et al. (2012), o $\mathrm{CO}_{2}$ é considerado o gás que mais contribui para a intensificação do efeito estufa. As emissões provêm principalmente da queima de combustíveis fósseis (carvão, petróleo e gás natural) em usinas termoelétricas e indústrias, veículos em circulação e sistemas domésticos de aquecimento.

Os níveis de $\mathrm{CO}_{2}$ aumentaram em volume de 280 partes por milhão no período que antecede à revolução industrial para quase 360 partes por milhão nos dias de hoje. Nos últimos 70 anos houve um aumento médio de $0,6^{\circ} \mathrm{C}$ na temperatura da superfície do globo, cabe ressaltar que a velocidade e a intensidade observadas no aumento da temperatura nesse período são incompatíveis com os tempos necessários à adaptação natural dos ecossistemas (BNDES, 1999).

Para IPCC (2007), é provável que a elevação da temperatura média global verificada nos últimos 50 anos tenha sido causada principalmente pelo aumento antrópico das concentrações de gases de efeito estufa. Essas mudanças têm afetado o clima, o ciclo hidrológico e os eventos extremos, com impactos na disponibilidade dos recursos hídricos em âmbito global e regional.

O Brasil teve um aquecimento de $0,7^{\circ} \mathrm{C}$ nos últimos cinquenta anos, valor mais alto que a melhor estimativa de aumento médio global, de $0,64{ }^{\circ} \mathrm{C}$. Essas modificações se refletiram por todas as regiões do país nas últimas décadas (IPCC, 2007).

Em 2005 a Amazônia sofreu uma das secas mais intensas dos últimos cem anos, em 2009 as enchentes foram o resultado de chuvas extraordinariamente fortes na Região Norte e estiveram associadas às temperaturas mais altas que o normal na superfície do mar no oceano atlântico sul tropical, condições quase opostas às observadas durante a seca de 2005 (MARENGO et al., 2011). 
O ano de 2010 a seca afetou uma grande área que compreendia o noroeste, centro e sudoeste da Amazônia. As mudanças climáticas e o desmatamento diminuem a formação de nuvens sobre a floresta, consequentemente poucas nuvens e menos chuvas também se traduziram em temperaturas mais altas e baixas históricas no nível do principal afluente, o Rio Negro. As secas de 2005 e 2010 foram semelhantes em termos de gravidade (BRASIL. MINISTÉRIO DO MEIO AMBIENTE, 2013).

A Região Sul do Brasil tem ficado exposta a períodos de seca muito severos. No período de 2004 a 2006, picos de temperaturas extremas também foram observados com mais frequência. Devido à seca houve perda de 8,5 milhões de toneladas de grãos (soja, milho e feijão), com um prejuízo de 3,64 bilhões e 451 municípios em situação de emergência ou estado de calamidade. Além disso, esta região foi palco de tempestades violentas e tornados mais frequentes (MARENGO et al., 2011).

O território brasileiro como um todo tem apresentado diferentes transformações no padrão espacial de uso e cobertura da terra nas últimas décadas. A cobertura vegetal da superfície continental tem sido consideravelmente alterada pelas atividades humanas, principalmente através da conversão em grande escala da vegetação natural por áreas de cultivos e pastagens. Essas mudanças na cobertura da superfície podem alterar o clima regional e global por meio de processos biofísicos e biogeoquímicos (CUNHA, 2012).

Para Ross (2001), os processos de degradação produzem consequências sobre os diferentes componentes ambientais, tais como a eliminação da cobertura vegetal original e presença de uma cobertura invasora e a perda parcial ou total do solo devido a fenômenos físicos (erosão) ou químicos (salinização e alcalinização).

As mudanças climáticas podem produzir impactos sobre a saúde humana por diferentes vias, de forma direta como no caso das ondas de calor ou mortes causadas por eventos extremos como as inundações. Outras vezes ocorre impacto de maneira indireta, sendo mediado por modificações no ambiente como a alteração de ecossistemas e de ciclos biogeoquímicos, que podem aumentar a incidência de doenças infecciosas.

Segundo Porto et al. (2011), o clima é um determinante da distribuição de vetores e agentes patogênicos. O aumento da incidência e prevalência de doenças como malária, dengue, febre amarela, hantavirose, entre outras, tem sido associadas às modificações climáticas.

As alterações extremas de temperatura também irão contribuir para o aumento da poluição do ar e da água, escassez de alimentos e elevação dos níveis de ozônio, o que agrava as doenças cardiovasculares e respiratórias intensificando alergias a pólen e outros alergênicos.

A concentração de poluentes acelera o desenvolvimento de disfunções respiratórias como gripes e resfriados, sendo considerados graves porque afetam pessoas dos extremos da pirâmide populacional: crianças até cinco anos e idosos. 
A formação de ilhas de calor agrava o quadro de saúde de hipertensos e pode aumentar o número de mortes. Nas cidades a elevação das temperaturas devem produzir dias e noites mais quentes exigindo revisão do uso das edificações, assim como políticas e ações de saúde mais eficientes (RIBEIRO, 2008).

A alteração no ritmo das chuvas trás prejuízos na produção de alimentos principalmente em regiões mais pobres, o que aumentará a prevalência de desnutrição e subnutrição.

Segundo Carvalho et al. (2005), algumas culturas perenes como o café e a laranja devem migrar para o sul devido as temperaturas mais adequadas para esse cultivo, já outras como arroz, feijão e milho atualmente cultivadas em todas as regiões do país como subsistência na agricultura familiar ou em larga escala devem se concentrar na Região Centro-Oeste.

Secas mais intensas e prolongadas deverão afetar ainda mais a Região Nordeste, mais especificamente o semiárido, além disso, o abastecimento de água potável também será afetado. Os eventos extremos introduzem considerável flutuação que podem afetar a dinâmica das doenças de veiculação hídrica, como a leptospirose, as hepatites virais e as doenças diarreicas, essas doenças podem se agravar com as enchentes ou secas que afetam a qualidade e o acesso à água.

As doenças respiratórias são influenciadas por queimadas e os efeitos de inversões térmicas que concentram a poluição, impactando diretamente a qualidade do ar, principalmente nas áreas urbanas. As regiões metropolitanas ficarão ainda mais quentes, susceptíveis a mais inundações, enchentes e desmoronamentos em áreas de risco. Os grandes períodos de estiagem também afetarão o fornecimento de energia devido ao baixo nível das hidrelétricas (INSA, 2013).

Não se pode dimensionar ao certo o volume das chuvas torrenciais concentradas em determinados períodos, ainda que possam ser estimadas, as mudanças vão gerar acontecimentos em intensidade desconhecida. As alterações do clima trarão repercussões sobre as cidades trazendo insegurança perante a falta de maior precisão do aumento da temperatura nos próximos cem anos e indeterminação quanto aos impactos socioambientais.

Outro efeito do aquecimento global será a maior incidência de pragas urbanas, já que temperaturas mais altas propiciarão a ocorrência em maior escala de insetos como cupins e pernilongos, entre outros, que afetam a qualidade de vida dos habitantes e contribuem para o adoecimento da população.

Condições sociais como situação de moradia, alimentação e acesso aos serviços de saúde somados a exposição a poluentes atmosféricos são fatores que aumentam a vulnerabilidade de populações expostas aos eventos das mudanças climáticas, estes poderão apresentar efeitos sinérgicos com agravamento de quadros clínicos em zonas rurais e urbanas, recaindo sobre populações mais vulneráveis e aumentando a demanda e gastos de serviços de saúde.

Ribeiro (2008) afirma que o quadro social do país agrava os impactos socioambientais das mudanças climáticas nas cidades brasileiras. Encontramos no 
Brasil uma parcela da população que pode se adaptar muito bem às consequências das mudanças climáticas nas cidades, no entanto a grande maioria está sujeita a riscos e não tem condições de enfrentar os desafios que os cenários indicam.

\section{PERSPECTIVAS DE CONVIVÊNCIA COM O NOVO CENÁRIO}

Perante os múltiplos impactos sociais, ambientais e econômicos possíveis é de fundamental importância a verificação de alternativas sustentáveis para o semiárido brasileiro, já que o quadro aponta que este será o local de maior conflito pelos aspectos já presentes e as poucas tecnologias disponíveis.

Podemos destacar a articulação entre os governos federal, estaduais e municipais com a criação de políticas públicas envolvendo mudanças climáticas como um modo de gerar e disseminar o conhecimento necessário para que se respondam os desafios representados pelas mudanças climáticas globais e regionais e seus efeitos na economia, no meio ambiente e na sociedade.

A criação da rede brasileira de Pesquisas Sobre Mudanças Climáticas Globais (REDE CLIMA) e o Instituto Nacional de Ciência e Tecnologia em Mudanças Climáticas (INCT-MC) pelo Ministério da Ciência e Tecnologia é um passo importante neste percurso.

Uma maneira efetiva para a mitigação dos efeitos das mudanças climáticas é o aumento da cobertura vegetal, tanto através do replantio de extensas coberturas florestais com o fim de remover $\mathrm{CO}_{2}$ atmosférico, quanto pelo efeito das florestas no ciclo hidrológico, além da preservação de florestas intocadas.

A arborização das vias, praças e áreas públicas colabora para aumentar o sombreamento e a evapotranspiração levada a efeito durante a fotossíntese, contribuindo diretamente para reduzir o acentuado aumento de temperatura do ar registrado em centros urbanos.

Deverão existir programas continuados de investimento em educação de crianças e jovens no país não somente em educação ambiental, mas levando em consideração a preparação para conviverem de maneira harmônica com o meio ambiente com condições competitivas na economia.

Por outro lado a adoção de medidas específicas para o semiárido nordestino inclui a redução da degradação da caatinga, a substituição da lenha e do carvão vegetal por dispositivos movidos à energia solar, a preservação de áreas protegidas para que se possam manter as espécies endêmicas de fauna e flora.

O convívio com a seca deve ser uma questão tratada não apenas como um fator climático, mas também como uma questão política, social e de saúde pública que preserve o homem em seu local e para isso as políticas públicas são fundamentais ofertando educação, saúde e técnicas de manejo no semiárido. 
Explorar as potencialidades do semiárido de forma sustentável e economicamente viável exige a compreensão de que a natureza tem de ser respeitada, é ela que deve determinar a forma e a época em que as atividades agrícolas devem ser realizadas, o que é necessário é aprender com a diversidade da natureza dessa região e pensar a semiaridez como vantagem e não como uma desvantagem.

A criação extensiva e as queimadas são um dos importantes fatores da desertificação e este é um determinante das elevadas temperaturas, assim técnicas especificas podem mitigar esse contexto e contribuir para amenizar os impactos do clima no semiárido.

A vegetação da caatinga é rica em espécies forrageiras nos extratos arbustivo, arbóreo e herbáceo que podem alimentar os animais, o uso de leguminosas pode reduzir a escassez de forragem em épocas de grande estiagem. O cultivo de lavouras xerófilas como a maniçoba e a palma forrageira é uma alternativa para a manutenção da alimentação animal, sem degradar a cobertura vegetal. O manejo produtivo da caatinga inclui o potencial forrageiro e os sistemas agrossilvipastoris.

Quanto à escassez das chuvas o uso e o aproveitamento sustentável da água é fundamental, são apontadas além do programa de cisternas, a implantação de barragens subterrâneas o que permitirá ao agricultor a formação de vazantes que são economicamente importantes para aquisição de emprego e renda familiar.

As agroflorestas também são uma alternativa de convivência com o semiárido além de representar um fator importante para diminuir o impacto das mudanças climáticas, favorecendo ao mesmo tempo a economia local, espécies como andiroba, copaíba, cedro entre outras são utilizados como madeira, óleos essenciais e matéria prima para cosméticos.

A erosão é considerada o principal fator de degradação do solo. É um processo através do qual as partículas do solo são deslocadas e removidas para outros locais pela ação da água ou do vento. Isso tem provocado, ao longo dos anos, redução da área agrícola, baixo rendimento das culturas e assoreamento de rios e reservatórios, com graves prejuízos à produtividade, à integridade do meio ambiente e à rentabilidade do agricultor.

A compostagem e a cobertura vegetal já morta podem servir de alternativa a agricultura, conservando não somente o solo, mas também a água, através da cobertura com bagana de carnaúba ou bucha de coco.

As consequências das alterações do clima para a saúde também podem ser minoradas através de medidas preventivas como melhorar os sistemas de vigilância para que sirvam de alerta para o controle de doenças infecciosas ou dos vetores, informar ao público como se proteger, vacinar e tratar rapidamente a população em risco. 


\section{CONSIDERAÇÕES FINAIS}

Após o reconhecimento crescente da forma profunda como as mudanças climáticas já estão atingindo as sociedades ao redor do globo e que virão a atingir no futuro em larga escala, governos nacionais, estaduais e municipais em vários países estão se preparando.

Os primeiros passos foram dados com os tratados globais na área do meio ambiente como a Conferência de Estocolmo, a ECO-92, a Convenção-Quadro sobre mudança do clima e sobre biodiversidade que demonstraram a preocupação crescente com a degradação ambiental do planeta e desencadearam políticas globais e nacionais para compreender e atuar no combate as mudanças do clima.

Embora muito tenha deixado de ser feito essas convenções representaram uma evolução na questão ambiental, uma ruptura nas visões tradicionais sobre o meio ambiente, causou um impacto expressivo sobre nações desenvolvidas e trouxe à existência a voz de nações subdesenvolvidas.

Apesar da convenção sobre mudanças climáticas não ter produzido imediatamente efeitos práticos, cinco anos depois levou ao nascimento do Protocolo de Quioto e repercutiu sobre diversas nações.

A biodiversidade é a principal riqueza dos seres humanos, dela retiramos alimento, remédios, matéria prima. A convenção sobre biodiversidade foi proposta a fim de harmonizar divergências entre países desenvolvidos e países de terceiro mundo, defendendo um uso sustentável dos recursos naturais, porém ainda muito pouco se fez neste sentido e há necessidade de avanços quanto à propriedade dos recursos biológicos.

O regime de mudança climática é um dos mais complexos e relevantes porque implica profundas inter-relações entre a economia e o ambiente global.

O global e o local estão cada vez mais ligados. As mudanças globais interferem na distribuição de organismos, promovem alteração na composição de comunidades e influenciam a produtividade dos ecossistemas, assim como condicionam e determinam o aparecimento de doenças.

Atualmente são percebidos efeitos adversos como o aumento do nível do mar, alteração no suprimento de água doce, maior número de ciclones, tempestades de chuva e neve intensas e mais frequentes além de forte e rápido ressecamento do solo.

Todas as regiões brasileiras já são afetadas pelas mudanças do clima, no entanto, a Região Nordeste possui um quadro que inspira mais cuidados uma vez que possui grandes problemas socioambientais aliados a sua constituição geomorfológica. Um monitoramento ambiental para aplicação em saúde abrange diversos agravos e fatores como queimadas, desmatamentos, enchentes, secas, 
urbanização, entre outros, a interação entre esses fatores é complexa e carregada de incertezas.

As possibilidades de convivência com o semiárido coexistem com as tradições e a cultura do povo nordestino. Dessa maneira, os antigos discursos e conflitos de interesses de Estocolmo 72 ainda refletem no semiárido a partir das relações de poder existentes nesses territórios, onde o capitalismo industrial, o Estado clientelista, entra em embates constantes com as reais necessidades de um povo, a preservação das suas tradições, cultura, formas econômicas e a conservação ambiental.

As mudanças climáticas projetadas indicam maiores temperaturas e menores precipitações, considerando a alta variabilidade, ações para aumentar a sustentabilidade deveriam melhorar a resiliência e a estabilidade dos ecossistemas, entre estes, todo o bioma caatinga.

Sistemas de uso da terra baseados em espécies perenes, em contraposição a anuais, devem ser mais estáveis e, portanto mais adequados para enfrentar os potenciais aumentos na variabilidade climática.

O combate à desertificação com vistas ao seu desenvolvimento sustentável deverá ter como objetivo a prevenção e/ou redução da degradação das terras assim como a reabilitação de terras degradadas.

A implantação do sistema agrossilvipastoril no semiárido pode resultar em diversos benefícios potenciais como: contribuir para o uso sustentável de pastagens cultivadas, recuperar áreas degradadas, melhorar as condições sociais e econômicas das famílias, preservar os recursos naturais, além de valorizar as propriedades e contribuir de maneira efetiva para redução das alterações do clima.

Variáveis como idade, perfil de saúde, resiliência fisiológica, localização geográfica, condições socioambientais contribuem diretamente para as respostas humanas relacionadas às variáveis climáticas, colocando o setor saúde frente a grandes desafios.

A avaliação dos efeitos das mudanças climáticas sobre a saúde e o meio ambiente é bastante complexa e requer uma avaliação integrada para analisar as relações entre os sistemas socioeconômicos, biológicos e ecológicos, com uma abordagem interdisciplinar dos profissionais de saúde, climatologistas, cientistas sociais, biólogos, epidemiologistas, entre outros.

\section{REFERÊNCIAS}

ANDRADE, Eunice; PEREIRA, DANTAS, Éden. Semiárido e o manejo dos recursos naturais: uma proposta de uso adequado do capital natural. Universidade Federal do Ceará. Fortaleza, 2010. 
BANCO NACIONAL DE DESENVOLVIMENTO ECONÔMICO E SOCIAL (BNDES). Efeito estufa e a convenção sobre mudança do clima. 1999. Disponível em: <http://www.bndes.gov.br/SiteBNDES/export/sites/default/bndes_pt/Galerias/Arquivo s/conhecimento/especial/clima.pdf>. Acesso em: maiO 2013.

BARBIERI, J. C. Gestão ambiental empresarial. São Paulo: Saraiva, 2007.

BRASIL. MINISTÉRIO DA CIÊNCIA TECNOLOGIA E INOVAÇÃO - MCTI. Convenção sobre Mudança do Clima. Disponível em: <http://www.mct.gov.br/upd_blob/0005/5390.pdf>. Acesso em: jun. 2013.

BRASIL. MINISTÉRIO DO MEIO AMBIENTE. Convenção sobre a diversidade biológica. Brasil: 2000. Disponível em: <http://www.mma.gov.br/biodiversidade/ convencao-da-diversidade-biologica>. Acesso em: ago. 2013.

CARVALHO, Paulo Gonzaga M. de et al.. Gestão local e meio ambiente. Ambiente \& Sociedade, v. 8, n. 1, jan./jun. 2005.

CUNHA, Ana Paula Martins do Amaral; ALVALÁ, Regina Célia dos Santos; OLIVEIRA, Gilvan Sampaio de. Impactos das mudanças de cobertura vegetal nos processos de superfície na região semiárida do Brasil. Revista Brasileira de Meteorologia, v.28, n.2, 139 - 152, 2013.

INSTITUTO NACIONAL DO SEMIÁRIDO (INSA). Disponível em:

$<$ http://www.insa.gov.br/wp-content/themes/insa_theme/acervo/painelbrasileiro.pdf $>$. Acesso em: jul. 2013.

INTERGOVERNMENTAL PANEL ON CLIMATE CHANGE. IPCC. Fourth

Assessment Report: Climate Change 2007: Working Group II: Impacts, Adaptation and Vulnerability. Disponível em: <http://www.ipcc.ch/publications_and_data/ publications_and_data_reports.shtml\#1> Acesso em: jul. 2013.

MARENGO, José A. (Coord.) et al. Riscos das Mudanças Climáticas no Brasil. Projeto colaborativo realizado pelo Centro de Ciência do Sistema Terrestre (CCST) do Instituto Nacional de Pesquisas Espaciais (INPE) do Brasil e o Met Office Hadley Centre (MOHC) do Reino Unido. 2011. Disponível em: <http://mudancasclimaticas. cptec.inpe.br/ rmclima/pdfs/destaques/relatorio_port.pdf>. Acesso em: ago. 2013.

MENEZES, R.S.C. Ciclagem biogeoquímica em ecossistemas terrestres do bioma caatinga. Braz. J. Biol., 2012, vol. 72, no. 3 (supl.), p. 643-653. Disponível em: <http://www.insa.gov.br/wp-content/themes/insa_theme/acervo/caatingabiome.pdf> Acesso em: jul. 2013.

NOBRE, P. Mudanças climáticas e desertificação: os desafios para o estado brasileiro. In: BRASIL. MINISTÉRIO DE CIÊNCIA E TECNOLOGIA. Desertificação e mudanças climáticas no semiárido brasileiro. Campina Grande, PB: INSA-PB, 2011.

PEARSON. Gestão ambiental. São Paulo, 2011. 
PORTO, Marcelo Firpo de Souza; SCHÜTZ, Gabriel Eduardo. Gestão ambiental e democracia: análise crítica, cenários e desafios. Ciência \& Saúde Coletiva, v. 17, n. 6, p.1447-1456, 2012.

RIBEIRO, Wagner Costa. Impactos das mudanças climáticas em cidades no Brasil. Parcerias Estratégicas. Brasília, DF. N.27, Dezembro 2008.

ROSS, J. L. S. Geografia do Brasil. 4.ed. São Paulo: Editora da Universidade de São Paulo, 2001.

SILVA, José Irivaldo Alves Oliveira. Conservação de recursos naturais no semiárido e desenvolvimento: análise do caso das reservas privadas. Ambiente \& Sociedade, São Paulo v. 16, n. 1 p. 79-98, jan./mar. 2013.

VENTURA, Andréa Cardoso; GARCÍA, Luz Fernandez; ANDRADE, José Célio Silveira. Tecnologias sociais: as organizações não governamentais no enfrentamento das mudanças climáticas e na promoção de desenvolvimento humano Social. Cad. EBAPE.BR, Rio de Janeiro, v. 10, n. 3, artigo 8, set. 2012 p.605-629.

VIOLA, Eduardo. O regime internacional de Mudança climática e o Brasil. Revista Brasileira de Ciências Sociais, v. 17, n. 50, out./2002.

Artigo recebido em: 30/01/2015

Artigo aprovado em: 25/11/2015 